\title{
BACTERAEMIA IN ASYMPTOMATIC HUMAN SUBJECTS
}

\author{
R. N. Hockett, W. J. Loesche and T. M. SODEman \\ Dental Research Institute and Department of Oral Biology, University of Michigan \\ School of Dentistry and Department of Pathology, University of Michigan \\ School of Medicine, Ann Arbor, Michigan 48104, U.S.A.
}

\begin{abstract}
Summary-The common occurrence of post-tooth extraction bacteraemia provides a convenient model system to evaluate techniques which demonstrate the magnitude of the bacteraemia. The system used continuous anaerobiosis and membrane filter recovery to quantitate bacteraernia. 19 of 22 pre-extraction blood samples and 20 of 22 post-extraction samples from hospitalized patients had one or more colonies per $5 \mathrm{ml}$ of blood. Colonies recovered averaged 7.3 per $5 \mathrm{ml}$ of blood for the pre-extraction samples and 10.7 for the post-extraction samples. 86 per cent of the pre-extraction bloods contained bacteria. 30 of 42 pre-extraction and 32 of 41 post-extraction samples from asymptomatic patients having teeth extracted had a bactersiemia which averaged about 5 colonies per $5 \mathrm{ml}$ of blood. Subsequent studies were concerned with the prevalance of detectable bacteraemia. In one series of presumably healthy blood bank donors, blood from 16 of 20 donors was positive for bacteria, with an average recovery of 11 organisms per $5 \mathrm{ml}$ of blood. In a second series, in which multiple samples were tested, 18 of 29 donors were positive with an average recovery of 2 organisms per $5 \mathrm{ml}$ of blood. The taxonomic characteristics of the isolates suggested that they could have originated from the intestine (Streptococcus faecalis), the skin (Propionibacterium acnes and Staphylococcus epidermidis) and the oral cavity (Actinomyces viscosus).
\end{abstract}

\section{INTRODUCTION}

Transient bacteraemias are associated with the extraction of teeth (Okell and Elliot, 1935; Bender et al., 1963; Martin, 1967) and with various forms of periodontal treatment (Cobe, 1945; Winslow and Kobernick, 1960). Positive cultures in post-extraction blood cultures average about 52 per cent (range from 17 to 86 per cent) (Khairat, 1966), which is considerably higher than the 10 to 15 per cent positive cultures reported for suspected bacteraemias unassociated with surgery (Ellner and Stoessel, 1966; Rosner, 1968; Morello and Ellner, 1969; Farmer and Komorowski, 1972). Post-extraction bacteraemias are of 5 to $20 \mathrm{~min}$ duration (Bender et al., 1963) and their significance in terms of systemic disease is not well understood (Martin, 1967), except in subacute bacterial endocarditis (Okell and Elliot, 1935; Wright, 1925).

The common occurrence of post-extraction bacteraemia provides a convenient model system to evaluate techniques which demonstrate the magnitude of the bacteraemia and which allow identification of the invading organisms. The bacteria introduced into the blood stream during tooth extraction should be members of the indigenous oral flora, some members of which could be killed by atmospheric oxygen during the time it takes to filter the blood and incubate the filter (Gordon, Stutman and Loesche, 1971; Loesche, 1969). Hence all procedures on blood samples must te performed in the absence of air.

\section{MATERIALS AND METHODS}

\section{Subjects}

The subjects were separated into three groups: hospitalized patients who were to have tooth extractions prior to surgical procedures (hospital group); asymptomatic subjects who came to the dental school for extraction of impacted third molars (clinic group); and asymptomatic, presumably healthy, persons who had been accepted as hospital blood bank donors (donor group). The hospital group was not on antibiotics, nor did they have signs of acute gingival or periapical infection about the extracted teeth. Patients in the hospital group were over $30 \mathrm{yr}$ old, whereas the subjects in the clinic and donor groups were mainly young adults. Those in the clinic and donor groups had a normal temperature at the time of blood collection. Blood from 114 persons was studied.

\section{Blood collection}

Blood samples were obtained from the median basilic vein of all subjects after the skin was scrubbed with Phisohex ${ }^{\circledR}, 70$ per cent ethanol and tincture of iodine. In the hospital and clinic groups, $5 \mathrm{ml}$ of blood were collected pre- and immediately postextraction and injected into sterile Vacutainer tubes (Becton-Dickinson LS3700). The tubes already contained $5.0 \mathrm{ml}$ of a filter sterilized $(0.22 \mu \mathrm{m}$ membrane filter) blood-collection solution (BCS) consisting of 10 per cent Gey's balanced salt solution (Grand Island Biological Laboratories) and 0.05 per cent sodium polyanethol sulphate (SPS; Grobax, Hoffman La Roche, Inc.) (Ellner and Stoessel, 1966; Finegold et al., 1967; Evans, Cekoric and Searcy, 1968).

In the first 20 subjects in the clinic group, blood was collected pre- and immediately post-extraction and inoculated into Vacutainer tubes containing $10 \mathrm{ml}$ of thioglycollate broth. Blood was obtained from the donors after the collection of a unit of blood. The plastic tubing of the collection unit was scrubbed 
with 70 per cent ethanol at a site about $50 \mathrm{~cm}$ removed from the venipuncture needle. A syringe needle was inserted through the tubing and 10 to $15 \mathrm{ml}$ of blood was removed and $5 \mathrm{ml}$ aliquots injected into the Vacutainer tubes containing the BCS. Thus direct contact with the donor's skin was avoided. Two series of donors were examined. In the first, the blood was collected by a technician and the needle used to puncture the tubing was also used to inject the blood through the septum of the Vacutainer tube into the BCS. In the second, the blood was collected by one of the investigators (TS), and the needle which punctured the tubing was replaced with a new needle which was used to inject the blood into the BCS. Minimal exposure of the blood to air occurred. Blood from the hospital and the donor groups was processed within 1 to $2 \mathrm{~h}$ after collection. Blood from the clinic group was processed within 5 to $15 \mathrm{~min}$ after collection.

The degree of difficulty of the extraction procedure and the length of time necessary for the extraction was recorded. One oral surgery resident collected the blood samples and performed the extractions in the hospital group and a second oral surgery resident collected the blood samples and performed the extractions in the clinic group.

\section{Processing of the blood}

The procedures used evolved during the course of the investigation and will be described according to groups and chronological development.

\section{Hospital group}

The blood samples were centrifuged in the Vacutainer tubes for $10 \mathrm{~min}$ at $3000 \mathrm{rpm}$ to sediment the blood cells. The unopened sample tubes were taken into an anaerobic glove box containing 85 per cent $\mathrm{N}_{2}, 10$ per cent $\mathrm{CO}_{2}$ and 5 per cent $\mathrm{H}_{2}$ (Aranki et al., 1969). The stoppers were removed and approximately 6 to $7 \mathrm{ml}$ of supernatant was aspirated by Pasteur pipette, avoiding the sediment, and placed into the top chamber of a plastic filtration unit (Sterifil, Millipore or Falcon, Bioquest). The chamber was capped and the supernatant filtered through a membrane filter $(0.45 \mu \mathrm{m}$ gridded cellulose, Millipore) using 25 psi negative pressure. The filters were washed by adding $30 \mathrm{ml}$ of sterile 0.85 per cent $\mathrm{NaCl}$ to the chamber and drawing this through the filter using negative pressure. The filtration unit was disassembled and the membrane filter placed with sterile forceps on the surface of MM10-sucrose agar plates (Loesche, Walenga and Loos, 1973). All filters were incubated at $35-37^{\circ} \mathrm{C}$ within the chamber for 4 to 7 days.

\section{Donor group}

In the first series of donor bloods, one $5 \mathrm{ml}$ sample was centrifuged and filtered as above, whereas the second sample was lysed by a solution containing 0.5 per cent Triton X-100 (Rohm and Haas) and 0.08 per cent $\mathrm{Na}_{2} \mathrm{CO}_{3}$ (Rose and Bradley, 1969) prior to filtration. This lysing fluid was filter-sterilized $(0.22 \mu \mathrm{m}$ filters) and $100 \mathrm{ml}$ aliquots were dispensed from a one litre intravenous (I.V.) bottle via sterile plastic tubing into the top chamber of the filtration units with minimal exposure to the glove box atmos- phere. The blood was removed from the Vacutainer tube by inserting a sterile syringe needle through the rubber stopper. It was then injected through the rubber cap of the filtration assembly directly into the lysing fluid. In this manner, minimal exposure to the chamber atmosphere occurred. The rubber surfaces through which the needle penetrated were scrubbed with 70 per cent ethanol. The blood-lysing fluid mixture was swirled for $10 \mathrm{~s}$ prior to filtration with negative pressure. The time required to accomplish filtration varied from 1 to $20 \mathrm{~min}$. The filters were washed with $30 \mathrm{ml}$ of sterile saline, placed on MM10sucrose agar and incubated as before in the glove box.

In the second donor series, a combination of the centrifugation and lysing procedures was employed. The Vacutainer tubes were inverted and centrifuged in this position at $3000 \mathrm{rpm}$ for $5 \mathrm{~min}$ to compact the blood cells. The tubes were maintained in the inverted position while introduced into the glove box. While the tube was still inverted, a sterile needle was inserted through the 70 per cent ethanol-scrubbed rubber stopper to a level at which its bevel was at the blood cell-supernatant interphase. The entire supernatant, the leucocytic layer and some red blood cells were removed by a syringe and injected into $100 \mathrm{ml}$ of the lysing fluid already in the top chamber of the filtration unit. This procedure reduced the time of filtration to 1 to 5 min thereby minimizing any deleterious effects the lysing solution may have on bacteria (Farmer and Komorowsk, 1972). The filters were washed with $30 \mathrm{ml}$ of saline, placed on MM10 sucrose agar and incubated at 30 to $37^{\circ} \mathrm{C}$ in the glovebox atmosphere.

\section{Clinic group}

These bloods were processed by the combined centrifugation and lysing procedure described above. The blood samples inoculated into the thioglycollate broth were incubated in the anaerobic glove box for 2 weeks.

\section{Controls for procedures used}

A separate filtration unit and filter was used for each of the 264 blood samples to prevent cross contamination between samples. Approximatcly 2 to 6 blood samples were processed at any given time. At each of the approximately 60 times that blood was processed, the 0.85 per cent $\mathrm{NaCl}$ washing solution and the lysing solution were freshly prepared and sterilized. The plastic tubing which delivered these fluids and the plastic filtration units were sterilized by ethylene oxide. On each occasion, a membrane filter (solution control) was placed in the filtration unit and first the lysing solution and then the washing solution were drawn through this filter by $25 \mathrm{psi}$ of negative pressure. The filter was removed, placed on MM10 sucrose agar and incubated for 7 or more days at 35 to $37^{\circ} \mathrm{C}$ in the anaerobic glove box. A second filter (atmosphere control) was not exposed to the solutions, but was placed directly on the surface of MM10 sucrose agar. The plastic lid of the Petri dish was removed and this filter was exposed to the anaerobic atmospherc of the glove box for approximately $30 \mathrm{~min}$.

Additional controls were performed in conjunction 
with the bloods obtained from the clinic group. A sample of the BCS, the blood lysing fluid and the saline washing solution that was used in the processing of each blood sample was inoculated into thioglycollate broth and incubated for 2 weeks in the anaerobic chamber. The efficacy of skin disinfection was monitored in the clinic group. Two to $3 \mathrm{ml}$ of MM10 sucrose agar was pipetted to sterile glass microscope slides which were individually placed in sterile Petri dishes. After solidification, the slides were incubated overnight to check for gross contamination and then kept in the refrigerator until needed. The oral surgeon removed the slide and pressed it against the skin of the antecubital fossa immediately after his disinfection procedure, but orior to venipuncture. These slides were incubated in the anaerobic glove box at 35 to $37^{\circ} \mathrm{C}$ for 7 days.

\section{Partial characterization of the isolates}

Isolates from the clinic and donor groups were Gram-stained and subcultured for identification. A single broth was used to determine indole production, nitrate and nitrite reduction, terminal $\mathrm{pH}$ in glucose and esculin hydrolysis (Loesche, Hockett and Syed, 1972). Confirmatory tests for representative isolates were made following procedures described by Facklam (1972), and Blair, Lennette and Truant (1970).

\section{RESULTS}

With all 3 separate experimental procedures the majority of asymptomatic subjects had a low level bacteraemia.

None of the isolates from the positive bloods appeared to have been introduced as a result of the various manipulative procedures performed in the anaerobic glove box. The glove box atmosphere was under constant surveillance. The only organism recovered on the exposed MM10-sucrose plates (atmosphere control) was Clostridium sporogenes, an organism which had been introduced into the glove box during studies on periodontal plaque (Loesche et al., 1972). This organism was found also on some of the filters (solution control), which had been exposed to the sterile lysing fluid and saline, and on some of the experimental filters. This contamination probably occurred during filtration or placement of the filters on the: agar plates. $\mathrm{Cl}$. sporogenes was considered to be a contaminant of the confined atmosphere of the anaerobic glove box and, whenever found, it was omitted from the data. No other organism was detected on the control filters.
The controls for the clinic group were the most extensive. Each sample of the blood collection solution was sterile, whereas 2 of the broth tubes containing the blood lysing fluid and 3 of the broth tubes containing the saline rinses were contaminated with Cl. sporogenes (Table 1). This organism appeared on 4 of the atmosphere control plates and apparently entered the broth from the constantly circulated chamber atmosphere during the long incubation period. The agar impression cultures obtained from the skin prior to venipuncture yielded Staphylococcus epidermidis on one occasion (Table 1).

\section{Hospital group}

The intent of this experiment was to quantitate the numbers of bacteria introduced into the blood stream as a result of tooth extraction. The blood was centrifuged and the supernatant filtered within 1 to $2 \mathrm{~h}$ after collection. Twenty of 22 post-extraction blood samples had 1 or more colonies per $5 \mathrm{ml}$ of blood (Table 2). However, 19 of 22 pre-extraction samples also had one or more colonies per $5 \mathrm{ml}$ of blood. All subjects had at least one positive culture. The number of colonies recovered averaged 7.3 per $5 \mathrm{ml}$ of blood for the pre-extraction samples and 10.7 for the post-extraction samples. The numbers of detectable bacteria in the blood after tooth extraction increased in 15 and decreased in 7 subjects. No identification of the colonies was performed, although on 2 occasions black pigmented colonies resembling $\mathrm{Bac}$ teriodes melaninogenicus were observed. The data weakly suggest that the level of bacteraemia increased following tooth extraction. The important observation was that the frequency of bacteracmia was essentially identical pre- and post-extraction. Inasmuch as these individuals were hospitalized for medical purposes with underlying dental problems, they could represent a population in which the risk to bacteraemia was quite high, even though at the time of sampling no evidence of acute infection was apparent.

\section{Donor group: series one}

In both donor series duplicate or triplicate $5 \mathrm{ml}$ volumes were obtained following the collection of a unit of blood. In the first donor series, one sample was prepared by centrifugation, whereas the other sample was lysed within the chamber immediately prior to filtration. The lysing procedure was introduced to determine whether the centrifugation procedure was underestimating the level of bacteraemia by sedimenting bacteria which were either within or adhering to the blood cells (Table 3). Eleven of 20

Table 1. Sterility controls for methodology used in bacteraemia studies

\begin{tabular}{lc}
\hline Condition or solution tested & Bacterial growth* \\
\hline 1. Blood collection solution (BCS) & $0 / 48$ \\
2. Blood lysing solution & $2 / 43 \dagger$ \\
3. Saline washing solution & $4 / 43 \dagger$ \\
4. Atmosphere control & $4 / 43 \dagger$ \\
5. Skin disinfection & $1 / 20 \ddagger$ \\
\hline
\end{tabular}

* Number of positive cultures/total number of cultures.

$\dagger$ The only contaminant recovered was $\mathrm{Cl}$. sporogenes.

$\ddagger$ The only contaminant recovered was Staph. epidermidis. 
Table 2. Bacteraemia in hospitalized oral surgery patients

\begin{tabular}{lcc}
\hline & Pre-extraction & Post-extraction \\
\hline $\begin{array}{l}\text { Frequency of } \\
\text { bacteraemia }\end{array}$ & $19 / 22(86)^{*}$ & $20 / 22\left(90^{\circ}\right)^{*}$ \\
$\begin{array}{l}\text { Aver. no. of CFU } \\
\text { per } 5 \text { ml of blood }\end{array}$ & $7.3(0-43) \dagger$ & $10.7(0-74)^{\dagger}$ \\
$\begin{array}{l}\text { No. of subjects in } \\
\text { which levels } \\
\text { increased } \\
\text { decreased } \\
\text { showed no change }\end{array}$ & \\
\hline
\end{tabular}

* Percentage frequency.

$\dagger$ Range.

centrifuged bloods and 16 of 20 lysed bloods were positive for bacteria. In most instances multiple colonies were found. Approximately 6 colonies per $5 \mathrm{ml}$ of blood were recovered from the centrifuged samples and 11 colonies per $5 \mathrm{ml}$ from the lysed samples. Only three subjects were negative for bacteraemia in both samples.

All colonies were subcultured and partially characterized (Table 4). In 12 individuals, a homogeneous group of Gram-positive, catalase-negative, alpha-haemolytic, chained, facultative cocci were isolated and identified as Streptococcus faecalis. These isolates fermented glucose, lactose and esculin, were unable to reduce nitrate or liquefy gelatin, were indole-negative, and grew at $45^{\circ} \mathrm{C}$, in 6.5 per cent $\mathrm{NaCl}$ and 40 per cent bile. These isolates gave a positive capillary tube precipitation with group D streptococcal antiserum (Difco). They ranged from 1 to 52 colonies per sample. Strains resembling Propionibacterium (Corynebacterium) acnes were catalase-positive, microaerophilic, non-branching coccalbacillary rods which fermented glucose, lactose and sucrose, reduced nitrate to nitrite, were esculin and indole-negative and grew on 40 per cent bile slants. They were found in 8 subjects and ranged from 1 to 30 organisms per sample. Other Gram-positive facultative cocci formed clusters and were catalase-positive, fermented glucose and sucrosc, werc gclatin-positive, reduccd nitrate to nitritc and grew in 40 per cent bile. These isolates were considered to be Staphylococcus epidermidis and were found in 8 subjects. Gram-positive, microaerophilic, branched rods which were catalase-positive and reduced nitrate to nitrite were identified as Actinomyces viscosus (Gerencser and Slack, 1969; Howell et al., 1965). These strains fermented glucose and sucrose, produced alpha haemolysis, produced acid in litmus milk and grew in 40 per cent bile broth. They were distinguished from $P$. acnes by virtue of their aerohic growth and Gram-stain morphology. However, this degree of characterization is not adequate to positively rule out that these strains might be some type of diphtheroid other than $A$. viscosus or $P$. acnes.

The majority of donors thus had a bacteraemia; the prevalence and magnitude of the bacteraemia was best demonstrated by the lysing procedure. The taxonomic characteristics of the isolates suggested that these organisms originated from the intestine (Strep. faecalis), the skin (P. acnes and Staph. epidermidis) or the oral cavity (A. viscosus).

\section{Donor group: series two}

Eleven of these 29 subjects ( 38 per cent) had no detectable bacteraemia (Table 3). Only one subject had all cultures positive, whereas 17 subjects had at least one of the samples positive. Forty-four of the 97 total blood cultures were positive. Approximately 2 colonies per $5 \mathrm{ml}$ of blood were found. Strep. faecalis was isolated from 8 subjects averaging 11 colonies per $5 \mathrm{ml}$ of blood (Table 4). P. acnes was found in 10 subjects avcraging 5 colonics (Table 4).

\section{Clinic group}

The preceding blood samples had been collected in the hospital and brought within 1 to $2 \mathrm{~h}$ to the

Table 3. Comparison of various processing procedures on bacterial recoveries from blood of blood bank donors

\begin{tabular}{lccc}
\hline \multicolumn{1}{c}{$\begin{array}{c}\text { Donor series } \\
\text { Processing }\end{array}$} & Centrifugation & Lysing & $\begin{array}{c}\text { 2nd } \\
\text { Centrifugation plus } \\
\text { lysing }\end{array}$ \\
\hline $\begin{array}{l}\text { Frequency of } \\
\text { bactcracmia }\end{array}$ & $11 / 20\left(55^{\circ}\right)^{*}$ & $16 / 20(80 \%)$ & $18 / 29(62 \%)$ \\
$\begin{array}{l}\text { Average no. of CFU } \\
\text { per } 5 \text { ml of blood }\end{array}$ & $5.6(0-20) \dagger$ & $11.2(0-54)$ & $1.8(0-59)$ \\
\hline
\end{tabular}

\footnotetext{
* Percentage frequency.
}

$\uparrow$ Range. 
Table 4. Bacterial species recovered from blood bank donors

\begin{tabular}{|c|c|c|c|c|}
\hline Series & Species & Ave. $/ 5 \mathrm{ml}^{*}$ & Range* & $\begin{array}{l}\text { Isolation } \\
\text { frequency }\end{array}$ \\
\hline \multirow[t]{4}{*}{$1+$} & Strep. faecalis & 13 & $1-52$ & $12 / 20$ \\
\hline & Staph. epidermidis & 5 & $1-20$ & $8 / 20$ \\
\hline & Prop. acnes & 9 & $1-30$ & $8 / 20$ \\
\hline & Actino. viscosus & 5 & $1-8$ & $4 / 20$ \\
\hline \multirow[t]{2}{*}{$2+$} & Strep. faecalis & 11 & $1-59$ & $8 / 29$ \\
\hline & $P$. acnes & 5 & $1-10$ & $10 / 29$ \\
\hline
\end{tabular}

laboratory. This transit time could have caused alterations in the levels of bacteria in the samples. Most blood samples were immediately inoculated into broth media, thereby eliminating any artifacts resulting from delays in culturing. An experiment was designed to minimize the effect of time on the culturing procedure and also to compare the filtration method with the broth cultures. Two $10 \mathrm{ml}$ blood samples were collected pre- and post-extraction from oral surgery patients who were having their teeth extracted in the dental school clinic. Five $\mathrm{ml}$ were inoculated into broth, whereas the second $5 \mathrm{ml}$ were immediately brought to the laboratory and processed using the combined centrifugation-lysing procedure. The broth cultures were positive only once in 40 cultures obtained from the first 20 subjects. Thirty-one of 40 filter cultures yielded positive bacterial growth in the same group of subjects. Further broth culturing was discontinued.

Bacteria were found in 69 per cent of the preextraction bloods and in 78 per cent of the postextraction bloods, averaging about 5 colonies per $5 \mathrm{ml}$ of blood in both groups. The isolates included strains of $P$. acnes, Staph. epidermidis, Streptococcus sp, Actinomyces sp, Bacillus sp and Gram-positive anaerobic cocci (Table 5). The streptococci and actinomyces were found in 1 pre-extraction sample but in
4 and 3 post-extraction samples respectively. $P$. acnes and Staph. epidermidis were the most frequently encountered organisms in both groups.

All the clinic patients had a normal body temperature prior to extraction. There was no correlation between either difficulty of the extraction or length of time necessary for extraction and the post-extraction blood levels of bacteria.

\section{DISCUSSION}

A bacteraemia of 1 or more colonies per $5 \mathrm{ml}$ of blood in 73 per cent of the asymptomatic persons (Table 6) is an unusually high occurrencc of bacteracmia when compared to the values reported in medical cases of suspected bacteraemia i.e., 398 positive out of 3,554 bloods cultured (Farmer and Komorowski, 1972); 95 out of 1019 (Morello and Ellner, 1969); 314 out of 2180 (Rosner, 1968); or to the values obtained from asymptomatic individuals (Wilson, Van Scoy and Washington, 1975). The higher percentage recovery in our study could be due to several factors: (1) an increased recovery of skin contaminants; (2) the maintenance of continuous anaerobiosis during culturing; (3) the use of transport and growth media and surface growth techniques which optimize the growth of bacteria.

Table 5. Bacterial species recovered from blood obtained from ambulatory oral surgery patients

\begin{tabular}{lcccccc}
\hline & $\begin{array}{c}\text { Frequency of isolation } \\
\text { Pre- } \\
\text { extraction }\end{array}$ & $\begin{array}{c}\text { Post- } \\
\text { extraction }\end{array}$ & \multicolumn{2}{c}{$\begin{array}{c}\text { Number of colonies } \\
\text { per 5 ml of blood } \\
\text { Pre- } \\
\text { extraction }\end{array}$} & $\begin{array}{c}\text { Post- } \\
\text { extraction }\end{array}$ \\
\hline $\begin{array}{l}\text { P. acnes } \\
\text { Staph. epidermidis }\end{array}$ & $22 / 42$ & $24 / 41$ & $5.5^{*}$ & $(2.9) \dagger$ & $6.5^{*}$ & $(3.8) \dagger$ \\
Gram-positive & $5 / 42$ & $6 / 41$ & 6.4 & $(0.8)$ & 4.5 & $(0.7)$ \\
anaerotic cocci & $4 / 42$ & $4 / 41$ & 2.8 & $(0.3)$ & 1.3 & $(0.1)$ \\
Streptococcus sp. & $1 / 42$ & $4 / 41$ & 9.0 & $(0.2)$ & 1.0 & $(0.1)$ \\
Actinomyces sp. & $1 / 42$ & $3 / 41$ & 1.0 & $(0.02)$ & 3.3 & $(0.2)$ \\
Bacillus sp. & $1 / 42$ & $2 / 41$ & 18 & $(0.4)$ & 6.0 & $(0.3)$ \\
\hline
\end{tabular}

\footnotetext{
* Calculated by dividing total number of colonies by number of bloods with positive cultures for each species.

† Calculated by dividing total number of colonies by number of blood cultures i.e., 42 pre-extraction, 41 post-extraction.
} 
The bacteria isolated from the blood included organisms normally resident on the mucous membranes and skin of man. The recovery of these indigenous species would be expected if the epithelial cell barrier is penetrated by some members of the normal flora. Immunological data suggest that this can occur. Blood samples taken from asymptomatic individuals contain low titres of antibodies against a wide array of indigenous bacteria (Evans and Mergenhagen, 1965; Hofstad, 1974; Lehner et al., 1974; Rosebury, 1962). Peripheral blood lymphocytes undergo blast transformation when exposed to antigens obtained from members of the oral flora (Lehner et al., 1974; Baker et al. 1976). In the investigation by Baker et al. (1976), a strain of $P$. acnes was one of the most potent strains tested. These data suggest that species indigenous to the oral cavity gain sufficient access to the immunological mechanism of the body to elicit specific humoral and cellular antibody formation. Undoubtedly species inhabiting other mucous membranes and skin sites gain similar access to the body. Other investigators, with the exception of Reith and Squier (1932), who found streptococci, diphtheroids and staphylococci in 65 of 293 blood samples taken from apparently healthy persons, have not reported the recovery of indigenous species with the frequency we found. In fact diphtheroids and coagulase-negative staphylococci are usually considered as resulting from skin contamination of the blood during venipuncture (Sonnenwirth, 1973). This raises the question whether these indigenous bacteria are frequently present in the blood, but are not detected by routine culturing procedures, or the anaerobic filter culture is so sensitive that it detects skin contamination which goes undetected in broth cultures. Contamination with $P$. acnes and Staph. epidermidis could occur at the venipuncture site, but it is difficult to see how Strep. faecalis and $A$. viscosus contamination could also so occur.

In the donor group, contamination of the needle should have been reduced compared to other studies, as the blood was aseptically withdrawn from the tubing of the commercially supplied sterile blood unit, rather than directly from an arm vein. Also, the sample was collected after approximately $450 \mathrm{ml}$ of blood had passed through the tubing. If contamination of the needle used to puncture the skin had occurred, this end-stream sampling should have diluted the levels of any contaminants relative to most studies in which the first 5 to $10 \mathrm{ml}$ of collected blood is cultured. If skin contamination was continuously occurring while the needle was in place, then most of the blood units collected in this study were contaminated and one would suspect that units collected elsewhere, using similar standard procedures would also be contaminated. Agar impressions taken of the venipuncture site in the clinic group failed to grow any bacteria in 19 of 20 cultures. Although this finding does not demonstrate that the skin was sterile, it does suggest that the disinfection procedure was adequate in terms of reducing the surface bacterial count on the skin. Thus, although the presence of $P$. acnes and Staph. epidermidis in the bloods of these asymptomatic subjects might represent only skin contamination, the alternate possibility i.e., that these organisms were actually present in the blood, warrants some consideration. Certainly, there is abundant evidence that these species can be associated with endocarditis (Felner and Dowell, 1971; Fraser, Rossall and Dvorkin, 1967; Kaplan and Weinstein, 1969; Levin, 1966; Wilson and Stuart, 1965; Wittler et al., 1960).

Considerable information is available showing that the mucous membrane flora of mammals is comprised mainly of anaerobes (Rosebury, 1962) and that maximal recovery of these indigenous organisms requires the exclusion of atmospheric oxygen during the plating procedure (Aranki et al., 1969; Eller, Crabill and Bryant, 1971; Hungate, 1950; Loesche, 1969). Gordon et al. (1971) found that approximately 70 per cent of the cultivable bacteria in gingival plaque samples were killed by 10 to $20 \mathrm{~min}$ exposures to oxygen. If this is also true for the anaerobes in the intestinal tract and on skin, these organisms can only be quantitatively cultured on primary isolation by using procedures which provide continuous anaerobiosis, such as the roll tube (Hungate, 1950), or anaerobic chamber (Aranki et al., 1969) techniques. Inasmuch as members of the indigenous flora were suspected to be present in the bloods of these asymptomatic subjects, the blood samples were handled in the absence of oxygen; this might account for the high percentage of positive cultures we found. Anaerobic procedures for the broth culturing of blood or clinical specimens results in increased detection of bacteria when either anaerobic jars (Khairat, 1966; Rogosa et al., 1960) or pre-reduced media (McMinn and Crawford, 1970) are used.

An important consideration in the isolation of indigenous bacteria is the simulation of the natural environment in the growth media and gaseous atmosphere. MM10 sucrose appears to permit maximum isolation of dental plaque organisms (Syed and

Table 6. Frequency and level of bacteraemia in asymptomatic subjects

\begin{tabular}{lccc}
\hline & Frequency of bacteraemia & Level of bacteraemia \\
\hline Blood donors & & & \\
$\quad$ Series 1 & $16 / 20$ & $80 \%$ & $11.2 / 5 \mathrm{ml}_{\text {of blood }}$ \\
Series 2 & $18 / 29$ & $62 \%$ & 1.8 \\
Oral surgery patients pre-extraction & & 7.3 \\
Hospital & $19 / 22$ & $86 \%$ & 4.6 \\
Clinic & $30 / 42$ & $71 \%$ & \\
Totals & $83 / 113$ & $73 \%$ & \\
\hline
\end{tabular}

* Number of colonies per $5 \mathrm{ml}$. 
Loesche, 1973). Other studies have shown that M10 medium (Caldwell and Bryant, 1966) from which MM10 sucrose was derived, is a satisfactory medium for the isolation of bacteria from rumen fluid (Caldwell and Bryant, 1966), human faeces (Eller et al., 1971) and sludge (Mah and Sussman, 1971). As originally designed, M10 could substitute for a physiologic fluid i.e., rumen fluid, in the isolation of an indigenous flora. Its nitrogen, carbon, vitamin and mineral composition and concentration may more nearly simulate the various physiologic fluids that bathe the indigenous flora of man, than most commercially available media. The use of MM10 sucrose medium may have contributed to the high percentages of positive cultures encountered.

When duplicate blood samples from the clinic patients were processed as either filter cultures or broth cultures, the frequency of bacteraemia in the filter cultures wis much larger ( 78 per cent vs. 3 per cent). This difference may be explained by the following considerations. Filter cultures incubated aerobically are superior to broth and pour-plate cultures in the isolation of bacteria from blood of symptomatic patients (Winn et al., 1966; Sullivan et al., 1972, 1975). Filter cultures permit the removal of naturally occurring antibacterial substances in the blood (Austen and Cohen, 1963; Dubos, 1954) as well as the removal of antibiotics (Sullivan et al., 1975). In our study, the incubation of the filter culture under anaerobic condtions meant that the colony-forming units (cfu) trapped on the filter would not be exposed to oxygen and would have immediate access to the $\mathrm{CO}_{2}$ and $\mathrm{H}_{2}$ present in the gaseous atmosphere. These advantages would be absent or reduced in broth cultures.

The majority of the positive cultures were due to the presence of low levels of bacteria i.e. $\leq 5 \mathrm{cfu} / 5 \mathrm{ml}$ of blood. Presumably the broth media used in blood cultures should detect this size inoculum, as they are able to support the growth of low numbers of test organisms. However, in-vitro grown strains are used, which may differ in fundamental ways from the same strain when it is grown in vivo (Dubos, 1954). Broth media which may support growth of $1 \mathrm{cfu}$ of an invitro adapted culture, may be inadequate for the growth of $1 \mathrm{cfu}$ of the same culture grown in vivo. Thus this may be another advantage in the use of a filter surface over a broth for the isolation of small inocula from blood samples.

In our investigation no symptoms were noted in the subjects, so that the bacteraemias were without evident medical significance. The actual levels and incidence of bacteraemia probably reflect the interplay between the entry of new bacteria into the blood and the host's ability to destroy or scavenge them in the reticulo-endothelial system. These indigenous organisms are not likely to propagate in the body when the tissues are healthy. However, when the host tissue is damaged, such as occurs with defective heart valves, traumatized teeth or tissue, cancerous tissues, i.e. any site of relative anoxia and stasis where moderate anaerobes and microaerophilia bacteria could establish, indigenous bacteria might contribute to clinically manifest infections.

Acknowledgemerts - We are grateful to Dr. Royce Biers and Dr. Timothy Pickens for the collection of the blood from the oral surgery patients and to Mrs. Marilyn Woolfolk and Mrs. Joan Rowan for their technical assistance This investigation was supported by Public Health Service grants from the National Institute of Dental Research No. DE-03011-04 and No. DE-02731-06.

\section{REFERENCES}

Aranki A., Syed S. A., Kenney E. B. and Freter R. 1969 Isolation of anaerobic bacteria from human gingiva and mouse cecum by means of a simplified glove box procedure. Appl. Microbiol. 17, 568-576.

Austen K. F. and Cohn Z. A. 1963. Contribution of serum and cellular factors in host defense reactions. I. Serum factors in host resistance. New Engl. J. Med. 268, 933-938.

Baker J. J., Chan S. P., Socransky S. S., Oppenheim J. J. and Mergenhagen S. E. 1976. Importance of Actinomyces and certain Gram negative Anaerobic organisms in the transformation of lymphocytes from patients with periodontal disease. Infect. Immun. 13. 1363-1368.

Bender I. B., Seltzer S., Tashman S. and Mcloff G. 1963. Dental procedures in patients with rheumatic heart disease. Oral Surg. 16, 466-473.

Blair J. E., Lennette E. H. and Truant J. P. 1970. Manual of clinical microbiology. Am. Soc. Microbiol, Bethesda. 61-64.

Caldwell D. R. and Bryant M. P. 1966. Medium without rumen fluid for nonselective enumeration and isolation of rumen bacteria. Appl. Microbiol. 14, 794-801.

Cobe M. H. 1954. Transitory bacteremia. Oral Surg. 7. 609-615.

Dubos R. J. 1954. Biochemical Determinants of Microbial Diseases. pp. 12-64. Harvard Univ. Press, Cambridge, Mass.

Eller C., Crabill M. R. and Bryant M. P. 1971. Anaerobic roll tube media for nonselective enumeration and isolation of bacteria in human feces. Appl. Microbiol. 22. 522-529.

Ellner P. D. and Stoessel C. J. 1966. The role of temperature and anticoagulant on the in vitro survival of bacteria in blood. J. Infect. Dis. 116, 238-242.

Evans G. L., Cekoric T. and Searcy R. L. 1968. Comparative effects of anticoagulants on bacterial growth in experimental blood cultures. Am. J. Med. Tech. 34, 103-112.

Evans R. T. and Mergenhagen S. E. 1965. Occurrence of natural antibacterial antibody in human parotid fluid. Proc. Soc. exp. Biol. Med. 119, 815-819.

Facklam R. R. 1972. Recognition of group D streptococcal species of human origin by biochemical and physiological tests. Appl. Microbiol. 23, 1131-1139.

Farmer S. G. and Komorowski R. A. 1972. Evaluation of the sterifil lysis-filtration blood culture system. Appl. Microbiol. 23, 500-504.

Felner J. M. and Dowell Jr., V. R. 1971. Anaerobic bacterial endocarditis. New Engl. J. Med. 283, 1188-1192.

Finegold S. M., Ziment I., White M. L., Winn W. R. and Carter W. T. 1967. Evaluation of polyanethol sulfonate (Liquoid) in blood cultures. Antimicrob. Ag. Chemother. Am. Soc. Microbiol. 692-696

Fraser R. S., Rossall R. E. and Dvorkin J. 1967. Bacterial endocarditis occurring after open heart surgery. Can. med. Ass. J. 96. 1551-1558

Gerencser M. A. and Slack J. M. 1969. Identification of human strains of Actinomyces viscosus. Appl. Microbiol. $18,80-87$.

Gordon D. F., Stutman M. and Loesche W. J. 1971. Improved isolation of anaerobic bacteria from the gingival crevice area of man. Appl. Microbiol. 21, 1046-1050.

Hofstad T. 1974. Antibodies reacting with lipopolysaccharides from Bacteroides melaninogenicus, Bacteroides fragilis and Fusobacterium nucleatum in serum from normal human subjects. $J$. Infect. Dis. 129, 349-352. 
Howell A., Jr., Jordan H. V., Georg L. K. and Pine L. 1965. Odontomyces viscosus, gen. nov. spec. nov. A filamentous microorganism isolated from periodontal plaque in hamsters. Sabouraudia 4, 65-68.

Hungate R. E. 1950. The anaerobic mesophilic celluloytic bacteria. Bact. Rev. 14, 1- 49.

Kaplan K. and Weinstein L. 1969. Diphtheroid infections of man. Ann. intern. Med. 70, 919-929.

Khairat O. 1966. The non-aerobes of post extraction bacteremia. J. dent. Res. 45, 1191-1197.

Lehner T., Wilton J. M. A., Challacombe S. J. and Ivanyi L. 1974. Sequential cell-mediated immune responses in experimental gingivitis in man. Clin. exp. Immunol. 16, 481-492.

Levin J. 1966. Diphtheroid bacterial endocarditis after insertion of a Starr valve. Ann. Intern. Med. 64, 396-398.

Loesche W. J. 1969. Oxygen sensitivity of various anaerobic bacteria. Appl. Microbiol. 18, 723-727.

Loesche W. J., Hockett R. N. and Syed S. A. 1972. The predominant cultivable flora of tooth surface plaque removed from institutionalized subjects. Archs oral Biol. 17, 1311-1326.

Loesche W. J., Walenga A. and Loos P. 1973. Recovery of Streptococcus mutans and Streptococcus sanguis from a dental explorer after clinical examination of single teeth. Archs oral Biol. 18, 571-575.

Mah R. A. and Sussman C. 1967. Microbiology of anaerobic sludge fermentation. I. Enumeration of the nonmethanogenic anaerobic bacteria. Appl. Microbiol. 16, $358-361$.

Martin W. J. 1967. Bacteremia: Common pathogens and methods of management. Lancet 87, 439-449.

McMinn M. T. and Crawford J. J. 1970. Recovery of anaerobic microorganisms from clinical specimens in pre-reduced media versus recovery by routine clinical laboratory methods. Appl. Microbiol. 19, 207-213.

Morello J. A. and Ellner P. D. 1969. New medium for blood cultures. Appl. Microbiol. 17. 68-70.

Okell C. C. and Elliot S. D. 1935. Bacteremia and oral sepsis with special reference to the etiology of subacute endocarditis. Lancet 2. 869-872.

Reith A. F. and Squier C. J. 1932. Blood cultures of apparently healthy persons. $J$. Infect. Dis. 51, 336-343.

Rogosa M.. Hampp E. G., Nevin T. A., Wagner H. N., Driscoll E. J. and Baer P. N. 1960. Blood sampling and cultural studies in the detection of postoperative bacteremias. J. Am. dent. Ass. 60. 171-180.

Rose R. E. and Bradley W. J. 1969. Using the membrane filter in clinical microbiology. Medical Lab. 2, 4-9.

Rosebury T. 1962. Microorganisms Indigenous to Man. pp. 310-392, Blakiston, New York.

Rosner R. 1968. Effect of various anticoagulants and no anticoagulant on ability to isolate bacteria directly from parallel clinical blood specimens. Am. J. clin. Path. 49, 216-219.

Sonnenwirth A. C. 1973. Bacteremia-extent of the problem. In: Bacteremia, Laboratory and Clinical Aspects. (Edited by Sonnenwirth A. C.) pp. 3-14. Thomas, Springfield, III.

Sullivan N. M., Sutter V. L., Carter W. T., Attebery H. R. and Finegold S. M. 1972. Bacteremia after genitourinary tract manipulation: bacteriological aspects and evaluation of various blood culture systems. Appl. Microbiol. 23, 1101-1106.

Sullivan N. M., Sutter V. L. and Finegold S. M. Practical aerobic membrane filtration blood culture technique. Clinical blood culture trial. 1975. J. clin. Microbiol. 1, $37-43$.

Syed S. and Loesche W. J. 1973. Efficacy of various growth media in recovering oral bacterial flora from human dental plaque. Appl. Microbiol. 26, 459-466.

Wilson T. S. and Stuart R. D. 1965. Staphylococcus albus in wound infection and in septicemia. Can. med. Ass. J. 93, 8-16.

Wilson W. P., Van Scoy P. E. and Washington J. A. 1975. Incidence of bacteremia in adults without infection. $J$. clin. Microbiol. 2, 94-95.

Winn W. R., White M. L., Carter W. T., Miller A. B. and Finegold S. M. 1966. Rapid diagnosis of bacteremia with quantitative differential membrane filtration culture. $J$. Am. med. Ass. 197, 539-548.

Winslow M. and Kobernick S. D. 1960. Bacteremia after Prophylaxis. J. Am. dent. Ass. 61, 69-72.

Wittler R. G., Malizia W. F., Kramer P. E., Tuckett J. D., Pritchard H. N. and Baker H. J. 1960. Isolation of a corynebacterium and its transitional forms from a case of subacute bacterial endocarditis treated with antibiotics. J. gen. Microbiol. 23, 315-333.

Wright H. D. 1925. The bacteriology of subacute infective endocarditis. J. Path. Bact. 28, 541-578. 